\title{
Unilateral Hydronephrosis in an Adult Woman
}

\author{
Jhih-Syuan Liu ${ }^{1}$, Ying-Tang Wang ${ }^{2}$ and Shih-Hua Lin ${ }^{2}$
}

Key words: hydronephrosis, ovarian vein syndrome

(Intern Med 52: 935, 2013)

(DOI: 10.2169/internalmedicine.52.0064)

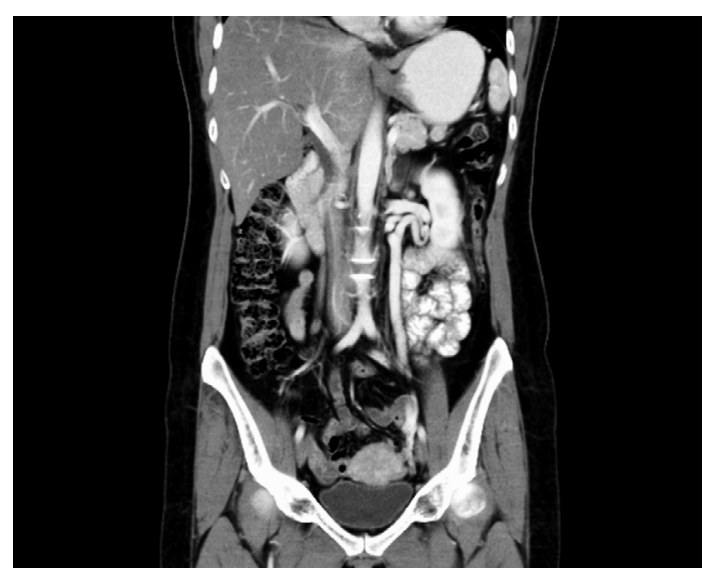

Picture 1.

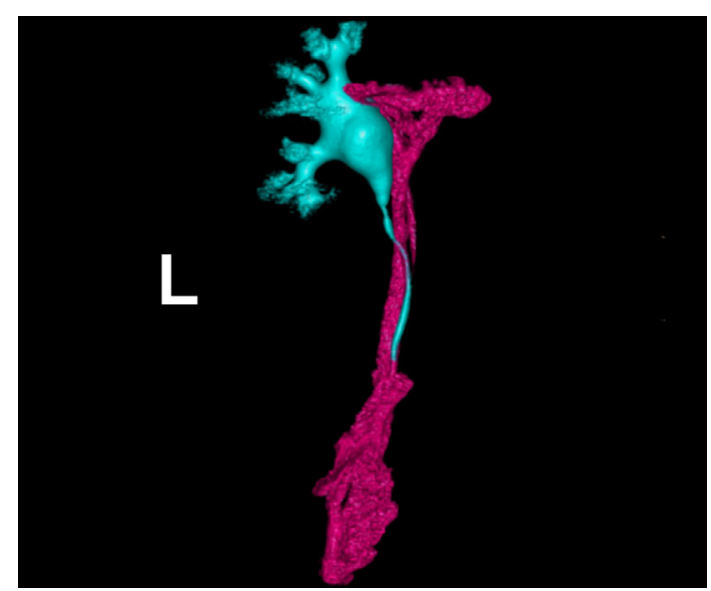

Picture 2.
A 39-year-old woman was referred for evaluation of an left hydronephrosis found on abdominal sonography. She had experienced lower back pain prior to her premenstrual period for one year. The results of a urinary analysis and the serum creatinine level were normal. Computed tomography (CT) of the abdomen and pelvis demonstrated that the left upper ureter was extrinsically compressed by a dilated ovarian vein (Pictures 1,2). The patient's effective renal plasma flow and glomerular filtration rate of the left kidney measured with technetium-99 $\mathrm{m}$ diethylene triamine pentaacetic acid were relatively normal. She was placed on regular follow-up without any surgical intervention.

Ovarian vein syndrome (OVS) was first described by Clark JC in 1964 and is defined as an abnormally dilated ovarian vein with extrinsic obstruction of the ureter (1), leading to intermittent flank pain. Contrast-enhanced CT is therefore effective for establishing the diagnosis of OVS (2). The management of OVS is usually conservative. OVS should thus be kept in mind as an important cause of hydronephrosis in female patients.

The authors state that they have no Conflict of Interest (COI).

\section{References}

1. Clark JC. The right ovarian vein syndrome. In: Clinical Urography: An Atlas and Textbook of Roentgenologic Diagnosis. 2nd ed. Emmett JL, Ed. Saunders, Philadelphia, 1964: 1227-1236.

2. Bhutta HY, Walsh SR, Tang TY, Walsh CA, Clarke JM. Ovarian vein syndrome: a review. Int J Surg 7: 516-520, 2009.

\footnotetext{
${ }^{1}$ Department of Internal Medicine, Tri-Service General Hospital, National Defense Medical Center, Taiwan and ${ }^{2}$ Division of Nephrology, Department of Medicine, Tri-Service General Hospital, National Defense Medical Center, Taiwan

Received for publication January 8, 2013; Accepted for publication January 14, 2013

Correspondence to Dr. Shih-Hua Lin, 1521116@ndmctsgh.edu.tw

(C) 2013 The Japanese Society of Internal Medicine Journal Website: http://www.naika.or.jp/imonline/index.html
} 